\title{
LOS MOVIMIENTOS DE RENOVACIÓN PEDAGÓGICA (MRP) EN LA ESPAÑA DE LA TRANSICIÓN EDUCATIVA (1970-1985)
}

\section{The Movements of Pedagogical Renewal (MRP) in Spain of the educational transition (1970-1985)}

José María Hernández DíAz

Universidad de Salamanca

Correo-e: jmhd@usal.es

Recepción: ro de febrero de 20I8. Envío a informantes: 25 de febrero de 2018 Aceptación definitiva: I8 de abril de 2018

RESUMEN: Los MRP son expresión pública de un momento histórico especial y excepcional de la España de la transición educativa (1970-1985). Son próximos y están hermanados con otros movimientos sociales que funcionan con mucha vitalidad en un contexto muy propicio para la emergencia de las libertades de todo tipo, a la salida de la férrea dictadura franquista. Los MRP tienen la aspiración colectiva, a veces romántica, de construir un mundo nuevo, una sociedad diferente y más justa, en este caso desde procesos de cambio en la política educativa y de renovación pedagógica. El paso de los MRP a grupos de renovación pedagógica más pequeños en su composición, y más centrados en aspectos pedagógicos específicos, se produce cuando el MEC, partidos políticos y sindicatos docentes canalizan otras aspiraciones existentes o nacidas incluso en el seno de los MRP. En nuestra opinión los MRP de esta etapa son la constatación de un activo y multiforme movimiento social gestado y construido en el ámbito de la educación, único en el mundo e irrepetible, propio del proceso sociopolítico vivido en la España de la transición educativa desde la dictadura franquista a la democracia.

Palabras clave: transición educativa; Movimientos de Renovación Pedagógica (MRP); España.

ABSTRACT: The MRP are public expression of a special and exceptional historical moment of the Spain of the educational transition (1970-1985). They are close and are twinned with other social movements that work with great vitality in a very 
favorable context for the emergence of freedoms of all kinds, at the end of the iron-fisted Franco dictatorship. The MRP have the collective aspiration, sometimes romantic, to build a new world, a different and more just society, in this case from processes of change in educational policy and pedagogical renewal. The shift from MRP to smaller pedagogical renewal groups in their composition, and more focused on specific pedagogical aspects, occurs when the MEC, political parties and teacher unions channel other aspirations existing or born even within the MRP. In our opinion the MRP of this stage are the verification of an active and multiform social movement gestated and built in the field of education, unique in the world and unrepeatable, typical of the socio-political process experienced in Spain of the educational transition since the dictatorship Francoist to democracy. Spain.

KeY WORDs: educational transition; Pedagogical Renewal Movements (MRP);

\section{Introducción}

$\mathrm{E}$ N LA EsPaña de la tRANSICión EDUCATIVA (I970-1985) se va a producir un fenómeno educativo único en el mundo, que no va a encontrar parangón en ningún otro sistema educativo occidental, ni menos aún en contextos menos desarrollados, al menos hasta la fecha.

Nos referimos a los Movimientos de Renovación Pedagógica (MRP), conformados por una masa crítica de profesores que en España, en algunos momentos de esta denominada transición educativa, llegó a movilizar y encuadrar a más de cincuenta mil docentes de todos los niveles, dispuestos a resistir y luchar por conseguir mejoras reales y estructurales en la educación del momento, a introducir innovaciones pedagógicas sustantivas, a mejorar sus condiciones formativas y profesionales, a defender una escuela pública de calidad para todos los ciudadanos. Los participantes activos lo hacían desde un perfil utópico, reivindicativo y propositivo de innovación pedagógica, y se erigían por momentos en sujeto político educativo alternativo al sistema educativo dominante, como vamos a ver más adelante.

La franja temporal de la transición que representa el paso de la dictadura franquista a la democracia representativa, en tiempos reales y cronológicos, viene siendo objeto de debate desde hace años entre historiadores. Los estudios de José María Maravall, Manuel Redero San Román, Santos Juliá y otros evidencian que en realidad debieran aceptarse diferentes transiciones, coexistentes en un tempus histórico con márgenes cronológicas estrictas o más flexibles, dependiendo del punto de vista adoptado ${ }^{\text {. }}$

Cfr. Maravall, José María: La política de la transición, Madrid, Taurus, 1985 (3. ${ }^{\text {a) }}$; Redero SAn Román, Manuel: «Apuntes para una interpretación de la transición política en España», Ayer, 36 (1999), pp. 26I-282; IDEM: Transición a la democracia y poder político en la España postfranquista (19751978), Salamanca, Libr. Cervantes, I993; Juliá, Santos (ed.): La transición a la democracia en España, Madrid, Marcial Pons, 1994; MAYORdomo PÉREz, Alejandro: «La transición a la democracia: educación 
LOS MOVIMIENTOS DE RENOVACIÓN PEDAGÓGICA (MRP) EN LA ESPAÑA

DE LA TRANSICIÓN EDUCATIVA (I970-I985)

JOSÉ MARÍA HERNÁNDEZ DÍAZ

Desde la perspectiva normativa y jurídica neta tal vez hay que aceptar que solo se puede hablar de transición desde la aprobación de la Ley para la Reforma Política aprobada dentro de las Cortes franquistas en noviembre de 1976, seguida de su aprobación en referéndum nacional (diciembre de 1976), hasta la promulgación de la Constitución política de 6 de diciembre de i978. Es posible que desde una lectura política algo más abierta habría que ampliar esa franja temporal desde la muerte de Franco (incluso un poco antes) hasta el fallido golpe de Estado de Tejero en febrero de I98I, o hasta la victoria del PSOE en las elecciones de 29 de octubre de 1982, que tranquilizó a millones de españoles y despejó muchas incertidumbres a otros. Incluso desde una perspectiva un poco más próxima a lo educativo nos parece que la transición educativa española, coincidiendo con la explosión social y económica de los años setenta, y también con los profundos procesos de cambio político y jurídico entonces vividos, deba extenderse desde el inicio de la puesta en marcha de la LGE de 1970 hasta el comienzo de la gestión socialista del sistema educativo en I983, ampliable a I985, una vez que se inicia la aplicación de la LRU (1983) y, sobre todo, la aprobación de la LODE (1985), ya que ambas representan cambios muy sustanciales de orientación en la política del Ministerio de Educación.

Varios de los artículos que componen los monográficos sobre el tema, aparecidos en revistas que se han aproximado al estudio de la transición educativa, como sucede con Revista de Educación (1992), Historia de la Educación (2002), o Educació i Història (20II), además de otros muchos textos dispersos en monografías y revistas, aceptarían esta propuesta, porque parece considerar lo unitario de la estructura del sistema educativo del momento, los conflictos de clase y los movimientos sociales que inciden directamente en las reformas, los procesos de innovación técnica en educación que representa la LGE de I970, las crecientes demandas de muchos profesores del momento en pro de la libertad política y sindical, de espacios autónomos de sociabilidad y de decididas reformas que debían procurar una educación pública innovadora y de calidad capaz de colaborar en la construcción de una sociedad más justa e igualitaria.

Conviene aclarar qué entendemos por Movimientos de Renovación Pedagógica (MRP), aunque resulta un tanto simplificador el deseo, dada la abundante literatura ya existente sobre el tema, de la que seleccionamos algunas entradas ${ }^{2}$.

y desarrollo político», Historia de la Educación. Revista Interuniversitaria, 2I (2002), pp. I9-47; HeRNÁNDEZ BELTRÁN, Juan Carlos: «Educar en tiempos de transición: significación educativa de los pactos de la Moncloa», Aula: Revista de Pedagogía de la Universidad de Salamanca, 14 (2002), pp. I43-154.

Elejabeitia; Carmen de; Redal, Pilar et al.: El maestro. Análisis de las Escuelas de Verano, Madrid, EDE, 1983; Vida Escolar, I983. Monográfico sobre los MRP de cada una de las Comunidades Autónomas de España; Bonafé Martínez, Jaume: «Diez años de renovación pedagógica organizada: invitación a una etnografía política», en Paniagua, J. y San Martín, Ángel (eds.): Diez años de educación en España (1978- 1988), Valencia, UNED, 1989, pp. 337-349; MATA I GARRIGA, Marta: «Historia de los Movimientos de Renovación Pedagógica. Crónica de los Mrp. Un siglo de renovación», Escuela Española, Madrid, número extraordinario, 3000 (I990); CARbonell, Jaume: «De la ley general de educación a la alternativa de escuela pública. Algunas notas introductorias sobre los movimientos sociales en el sector de la enseñanza», Revista de Educación, n. extraordinario (1992), pp. 237-255; 
LOS MOVIMIENTOS DE RENOVACIÓN PEDAGÓGICA (MRP) EN LA ESPAÑA

DE LA TRANSICIÓN EDUCATIVA (I970-I985)

JOSÉ MARÍA HERNÁNDEZ DÍAZ

Existen en España grupos de renovación pedagógica que antes, durante y después de esa tan especial franja histórica mencionada (1970-1985) llevan a cabo acciones puntuales o procesos de innovación y reforma pedagógica algo más permanentes en el tiempo y en algunos lugares y/o centros educativos públicos o particulares. Varios de estos grupos de renovación pedagógica participan del concepto más amplio de los MRP, se integran en ellos y se adscriben a una etapa histórica muy específica, la que abordamos aquí. Existen, sin duda, otras muchas experiencias de innovación pedagógica, que para nosotros no conforman los MRP, ante todo porque no se corresponden con el contexto de la España del momento, que nos parece ser la clave de interpretación más adecuada y convincente. No todo aquello que trata de cambiar o mejorar el sistema educativo es MRP, por lo que conviene advertirlo para no generar confusión.

Renovación pedagógica, innovación educativa, modernización pedagógica son sintagmas parecidos, que pretenden mejorar y reformar la educación, y que también están presentes en lo propio de los MRP. Pero nosotros pensamos que las señas de identidad más profundas de estos grupos más amplios que denominamos MRP pertenecen a una etapa histórica muy concreta de nuestro sistema sociopolítico y educativo, la que aquí estudiamos, y no a otras. En ella tal vez fuera más pertinente hablar de movimientos sociales en el ámbito de la educación.

Por ello, más allá de los grupos de renovación pedagógica que existieron por entonces, que algunos incluso nacen antes de 1970, y otros continúan funcionando en el presente siglo xxI, hemos de considerar los MRP de aquella etapa como plataformas amplias (muy amplias, asamblearias con frecuencia, y a veces desorganizadas, o poco sometidas a dictámenes jerárquicos); autónomas casi siempre; independientes y propias de los profesores; surgidas, apreciadas y vivificadas en la mayor parte de las entonces regiones y provincias de España; expresivas de un contexto de transición sociopolítica en el que no existían partidos políticos (o

Saenz Del Castillo, Andrés A.: «El (o)caso de los MrPs», Revista Electrónica Interuniversitaria de Formación del Profesorado, 2 (I) (1999), en línea, i2 pp.; Benejam Arguimbau, Pilar: «Las Escuelas Normales en tiempos de la transición", Historia de la Educación. Revista Interuniversitaria, $2 \mathrm{I}$ (2002), pp. 8I-90; CARBonell, Jaume: «Balance de tres décadas de renovación pedagógica», ConCiencia Social. Anuario de Didáctica de la Geografía, la Historia y las Ciencias Sociales, 8 (2004), pp. 65-82; LÁzaro Lorente, Luis Miguel: «Política y educación: la renovación pedagógica en España, I970-I983", en Candeias Martins, Ernesto (coord.): v Encontro Ibérico de Historia de la Educação. Renovação pedagógica, Castelo Branco, IPCB, 2005, pp. 347-394; Hernández DíAz, José María: «Associações de profesores e sindicatos em Espanha durante a transição da ditadura de Franco para a democracia (1970-1983)», Revista Lusófona de Educação, Lisboa, 22 (2012), pp. 13-38; HeRnÁNDeZ DíAz, José María: «Asociacionismo y sindicalismo docente durante la transición en España», Aula. Revista de Pedagogía de la Universidad de Salamanca, 20 (2014), pp. 135-158; Groves, Tamar: Teachers and the struggle for democracy in Spain, 1970-1985, London, Palgrave Macmillan, 20I4; Esteban FRADES, Santiago: «La renovación pedagógica en España: un movimiento social más allá del didactismo», Tendencias Pedagógicas, 27 (2016), pp. 259-284; MArTínez BonafÉ, Angels: «Els Moviments de Renovació Pedagògica: construint la democràcia des de les aules», Educació $i$ història: Revista d'història de l'educació, 27 (2016), pp. 83-Io5; Segovia Aguilar, Blas: «Los mrps. Un modelo de Formación del Profesorado comprometido en la defensa de la escuela pública», E-CO. Revista Digital de Educación y Formación del Profesorado, I4 (2017), pp. 450-468. 
JOSÉ MARÍA HERNÁNDEZ DÍAZ

acaban de ser legalizados), en el que no existen sindicatos libres de docentes (o eran muy bisoños y aún semiclandestinos); donde no existen espacios visibles de sociabilidad libre para los profesores; en el que la formación pedagógica ofrecida a maestros de primaria y profesores de segunda enseñanza en las entonces Escuelas Normales y en los Institutos de Ciencias de la Educación (ICE) era muy precaria, a veces desorientada e inoperante, o el riesgo de desprotección que se cernía sobre el derecho a la educación y la escuela pública era clamoroso, justamente en el momento crítico de la salida de la dictadura franquista.

Además, todavía en esos años que nos ocupan (1970-1985) el contexto de gestión de la educación en España era centralista, monolítico en toda expresión lingüística dentro de las instituciones escolares, uniformante y heredero de la tradición educativa del franquismo que aún revolotea como espada de Damocles en claustros escolares y prácticas de aula, cargado de represión contra lo nuevo y diferente, de conservadurismo ideológico y pedagógico, de elementos confesionales, control y oficialismo extremo desde el poder, lleno de precariedades en las infraestructuras educativas y en la condición social y salarial de los profesores. La administración y la inspección educativa en la mayoría de los casos vigilaba y castigaba siguiendo pautas del pasado inmediato mucho más que se dedicaba a supervisar y orientar pedagógicamente a los docentes.

La clave de comprensión de la originalidad de los MRP en los años que estudiamos viene derivada del contexto propio de una España que sale de la dictadura franquista, en la que balbucea la esperanza de una democracia real. Por tanto, cuando va cambiando ese marco de relaciones sociales y políticas se transforma también el cuadro de asuntos que afectan al sistema escolar, y los canales por donde se buscan y encuentran soluciones e innovaciones a la educación española. De ahí que la vitalidad alcanzada por los MRP entre 1970 y I985, cargada de esperanza renovadora para la educación española, nos parece que resulta irrepetible. Lo contrario simplemente nos parece una ensoñación, porque el contexto es el que manda en la educación.

\section{El contexto de la educación en España (1970-1985)}

El punto de partida para abordar los problemas de la educación en estos años se sitúa en el diagnóstico que el llamado Libro Blanco de la Educación de 1969 hace del deplorable estado de la educación en España, siguiendo criterios ponderados y legitimados desde instituciones internacionales reconocidas, como la unEsco, el Banco Mundial o el Fondo Monetario Internacional. Los resultados del informe son demoledores para las posiciones educativas del tardofranquismo, dada la inadecuación constatada entre el modelo de sistema escolar decimonónico aún vigente y las nuevas demandas formativas y culturales de una sociedad como la española que cambia de forma acelerada en esos años sesenta del desarrollismo. De ese informe, como es bien sabido, se deriva la propuesta y aprobación de la Ley General de Educación (LGE) de 1970 (la denominada Ley Villar Palasí), 
coincidiendo con la llegada al Ministerio de Educación del grupo de los llamados tecnócratas de la educación, muchos de ellos vinculados al Opus Dei, grupo de fuerte influencia en la macropolítica franquista por aquellas fechas.

El tracto histórico de la España que va de 1970 a 1985 en lo educativo se sitúa entre dos grandes leyes educativas, cuyo significado político educativo es muy diferente, pues cada una de ellas responde a problemas y contextos españoles muy distintos, a pesar de la proximidad cronológica existente entre ellas, de solamente quince años.

La LGE de septiembre de 1970, que goza de vigencia plena hasta 1985, año de aprobación de la Ley Orgánica del Derecho a la Educación (LODE), y en su estructura general la mantiene para el sistema educativo hasta 1990, cuando se aprueba la LOGSE, representa el osamento que sostiene el proceso modernizador de la educación en España, en su versión tecnocrática. Quedaba pendiente el imprescindible complemento democrático para su organización técnica y su respuesta social, en una España ciertamente distinta en muchos aspectos a la de los años sesenta. La LGE de 1970 modernizaba la educación desde una visión modernizadora y tecnocrática, pero sin admitir la democracia mínima exigible a toda normativa pedagógica propia de un país democrático, como la mayoría de los occidentales de entonces, y España en 1970 todavía no lo era.

De ahí que fuera imprescindible promulgar en 1985 la LODE, una norma que debería democratizar la original LGE de 1970, más aun cuando ya se había votado y aprobado una nueva Constitución política en 1978, ampliamente refrendada. Recordemos además que desde finales de 1982 comenzaba a gobernar en España el Partido Socialista Obrero Español (PSOE), una vez que había dimitido Adolfo Suárez como presidente del Gobierno (I98I) y se producía la debacle electoral de la Unión de Centro Democrático (UCD), coalición creada en su día con fuerzas políticas de procedencias muy diversas, algunas nacidas del seno profundo del régimen franquista.

Pero, además, y tal vez sobre todo, la educación del tardofranquismo buscaba implantar reformas técnicas en el obsoleto sistema educativo, obviando el clima real que se vivía en la calle, al margen de la emergente crítica política que se lanzaba a diario contra un sistema tan autoritario como el implantado en 1936, distanciado de los crecientes conflictos sociales aflorados desde las empresas y las administraciones públicas, desde los barrios de las ciudades y su reivindicativo movimiento ciudadano. Estaba claro que se agudizaban las contradicciones entre un sistema político en completo declive y en descomposición, y una oposición política, ciertamente diversificada y aún poco organizada, que salía de la clandestinidad o se distanciaba del régimen.

El sistema educativo español de esos años setenta, que preceden a la aprobación de la Constitución de 1978, reclamaba urgente atención para mejorar el funcionamiento de una LGE de 1970 que encontraba graves dificultades en su aplicación, que carecía de financiación apropiada para crear miles de puestos escolares que precisaban miles de niños en edad de escolaridad de las nuevas barriadas de las ciudades, a las que se habían desplazado millones de españoles procedentes 
LOS MOVIMIENTOS DE RENOVACIÓN PEDAGÓGICA (MRP) EN LA ESPAÑA

DE LA TRANSICIÓN EDUCATIVA (I970-I985)

JOSÉ MARÍA HERNÁNDEZ DÍAZ

del ámbito rural de cada provincia o de regreso de la emigración al extranjero. Era perentorio resolver el lastre de un problema arrastrado desde muy atrás, como era la mínima escolarización obligatoria de los españoles, entonces de los 6 a los I4 años, que requería crear muchas nuevas escuelas primarias y secundarias, ofrecer nuevas plazas para las demandas de estudiantes en las universidades y disponer de miles de profesores de todos los niveles del sistema educativo. Resultaba imperioso avanzar dentro del sistema educativo en la organización de una formación profesional, que durante décadas había permanecido bajo la órbita del Ministerio de Trabajo y de su ministro falangista, José Antonio Girón, y que resultaba completamente inoperante para las necesidades de una economía en creciente desarrollo, como la española de aquellos años. Había que resolver indefiniciones heredadas sobre el débil protagonismo del Estado en la educación y el peso tan notorio que en ella tenía asignado la Iglesia desde 1936 en adelante. El debate sobre la escuela pública y la escuela confesional, en sus aspectos teóricos y sus desarrollos prácticos, se convierte en una de las claves de esta corta pero intensa etapa.

Desde el punto de vista más estrechamente vinculado a los profesores, y por tanto a los nacientes MRP, era un clamor la debilidad de la formación recibida para su ejercicio profesional en Escuelas Normales y Facultades Universitarias, tanto como la precaria situación salarial de la mayoría de los profesores, el escaso número de puestos laborales en las instituciones educativas, la carencia absoluta de derechos democráticos y sindicales para los docentes.

Algunas de estas reivindicaciones y demandas fueron atendidas en los famosos Pactos de la Moncloa (octubre de 1977), considerados al principio de las negociaciones como condición previa para resolver una grave situación económica, pero de inmediato convertidos por los líderes y fuerzas negociadoras en imprescindibles para avanzar en el proceso político y constitucional posterior. Otras mejoras debieron esperar mejores oportunidades para ser atendidas, y en concreto a partir de la aprobación de la Constitución en diciembre de 1978.

Un clima de esperanza sociopolítica y educativa, también de incertidumbre, se abría en España por estos años, y en particular en torno al debate sobre escuela pública y/o privada, antes y después de 1978, sobre si prevalecía la igualdad en el acceso a la educación o la libertad de enseñanza, y las consecuencias que de ahí se derivan en la vida cotidiana de familias y ciudadanos. Confluían también otros factores, como la inmadurez y falta de rodaje de los bisoños partidos políticos y de sindicatos libres, pero también la carga utópica y esperanzada de miles de profesores ansiosos por alcanzar una escuela cercana a los intereses reales de la población.

La fragilidad política de los gobiernos de UCD entre los años críticos de 1979 y 1982 favoreció aún más la incertidumbre a la hora de articular políticas educativas visibles y coherentes que fueran más allá de propuestas puramente tecnocráticas o genéricamente modernizadoras. Es la etapa que coincide con la de mayor presencia pública de los MRP, con la de mayor peso específico de sus propuestas alternativas, en la que participa un mayor número de profesores en las Escuelas 
de Verano y otras actividades semejantes organizadas por los MRP (en torno a cincuenta mil docentes hacia 1980).

La llegada del PSOE al gobierno de España a finales de 1982 lleva consigo efectos inmediatos sobre el sistema educativo. Dada la personalidad, intereses directos y formación del nuevo ministro de Educación, José María Maravall, la Ley de Reforma Universitaria (LRU) se erige en prioridad, y pronto es aprobada (25 de agosto de 1983). Era urgente democratizar y racionalizar la universidad en España, y seguramente era una medida más sencilla que otras más influyentes sobre el sistema escolar no universitario, como luego se va a demostrar. Esta normativa de ámbito universitario no tiene impacto especial, decisivo y directo sobre los MRP, dado que la mayoría de los participantes en las actividades organizadas por aquellos desempeñan su trabajo en los niveles primario y secundario del sistema educativo.

La maquinaria normativa y de actividad febril de José María Maravall y sus colaboradores en el Ministerio de Educación también se manifiesta pronto de forma rápida y directa con los MRP desde febrero de 1983, como veremos, y con la creación de los Centros de Profesores en 24 de noviembre de 1984, orientados a la formación permanente de los docentes. Por supuesto, la discusión previa y aprobación de la LODE (1985), y las grandes movilizaciones impulsadas por los grupos conservadores en torno a ella, ofrecen un panorama nuevo a la vida cotidiana de los MRP y de miles de profesores. Eran las primeras grandes expresiones de la reforma educativa socialista que confluiría en la aprobación de la LOGSE en I990, precedida de un amplio y participativo debate educativo3.

Pero tan importante o más que estos factores, que consideramos como específicamente socioeducativos, es que debamos atender al impacto de todo lo que emerge en la ciudadanía en los años de la transición política española, y también desde movimientos sociales de dimensión internacional.

En realidad, por estos años nos encontramos en España ante un magma ciudadano en ebullición, e impreciso en sus magnitudes, desde el que aflora un conjunto nuevo de movimientos sociales emergentes, dentro de los que se insertan los MRP para el ámbito de la educación. Estamos hablando, claro está, de la defensa de los derechos políticos y sindicales de los ciudadanos y trabajadores, de los derechos de la mujer y del naciente feminismo, de los primeros pasos del ecologismo y de la sensibilidad medioambiental, de la liberación sexual y de los nuevos roles que piden ejercer hombres y mujeres de forma libre, de los movimientos asociativos en barrios de las ciudades y en algunas comarcas rurales en defensa de servicios básicos imprescindibles para una convivencia de calidad (entre ellos la defensa de la escuela rural y de instalaciones culturales dignas), de la influencia de los movimientos de liberación y descolonización en América Latina y África principalmente, del movimiento antimilitarista y de la objeción de conciencia, del pacifismo y del movimiento hippie, del protagonismo de los jóvenes en la vida pública y en la aparición de nuevos valores (mayo de 1968 está aún muy reciente

\section{Cfr. VARela, Julia: Las reformas educativas a debate (1982-2006), Madrid, Morata, 2007.}


LOS MOVIMIENTOS DE RENOVACIÓN PEDAGÓGICA (MRP) EN LA ESPAÑA

DE LA TRANSICIÓN EDUCATIVA (I970-I985)

JOSÉ MARÍA HERNÁNDEZ DÍAZ

y es un referente juvenil mundial), de la defensa de los derechos del consumidor y del consumerismo, de la lucha por el uso de las lenguas maternas en la escuela y en la vida pública y de la recuperación de derechos históricos en algunas regiones y nacionalidades, de la eclosión de movimientos europeístas y antifascistas. También hay que mencionar dentro de este gran movimiento ciudadano la presencia activa de algunos sectores de obispos, sacerdotes obreros y de cristianos de base comprometidos con la mejora social y el cambio político, de espíritu posconciliar vaticano, y que poco a poco soltaban amarras respecto a las ataduras históricas mantenidas por la Iglesia durante décadas con el franquismo.

Después del aislamiento de décadas sufrido en España por razones políticas parece descorcharse de forma impetuosa una gran botella llena de presiones sociales y ciudadanas que pugnan por aflorar, y lo hacen de manera explosiva y ansiosa. A todo ello se une el logro de la libertad de asociación, de prensa libre e imprenta, de la libertad de opinión y de cátedra, expresiones públicas que habían estado prohibidas y censuradas durante décadas, y que a la llegada de la democracia se erigen en instrumentos imprescindibles del nuevo modelo de convivencia y organización social.

Solamente desde este contexto de referencia, tan rico en manifestaciones, heterogéneo y complejo al mismo tiempo, podemos adentrarnos en la comprensión algo más particularizada de los MRP y su contribución socioeducativa a la historia de la educación contemporánea en España. Sobre todo, porque los MRP son expresión viva de esa coyuntura histórica, y no de otra, de ese tiempo medio en la historia contemporánea de España, utilizando la conceptualización braudeliana del tiempo histórico.

\section{Los MrP, de la clandestinidad a la vida pública y al reconocimiento oficial}

Es bien conocido el clima favorable a la renovación pedagógica que se vive en España antes de la Guerra Civil, y en particular en la etapa de la Segunda República. Experiencias y grupos de renovación pedagógica van a florecer en diferentes lugares de España, como algunos seguidores del ideario educativo de la Institución Libre de Enseñanza, experiencias pedagógicas de procedencia socialista (Escuela Nueva de Núñez de Arenas o de Cesáreo del Cerro) y anarquista (recuérdese la Escuela Moderna de Ferrer i Guardia y las Escuelas Racionalistas), incluso alguna emergida del ámbito católico como la de Andrés Manjón. Recordemos la Escola del Bosc y la figura de Rosa Sensat en el marco sociocultural catalán, los maestros practicantes de la pedagogía freinetiana que se despliegan por muchos lugares de la España rural y urbana, las primeras Escuelas de Verano en Barcelona desde 1914, así como los procesos pedagógicos relacionados con la implantación y posterior desarrollo de la escuela graduada y la llegada a España de experiencias de autores representativos del movimiento de la Escuela Nueva. De todas estas experiencias pedagógicas innovadoras se han publicado decenas de libros y artículos especializados, por lo que aquí no vamos a insistir en ello. Y tampoco 
vamos a reincidir ahora en el desastre que la Guerra Civil representa para la depuración, eliminación y vacío de todo signo de innovación pedagógica, contrario como es obvio a un modelo de pedagogía autoritaria de perfil nacionalcatólico como el dominante en años. Los restos de experiencias pedagógicas innovadoras anteriores a 1939 durante el franquismo permanecen ocultos o con muchas dificultades de supervivencia a lo largo de décadas.

La experiencia de la Asociación de Maestros Rosa Sensat en Barcelona a mediados de los años sesenta, de la mano de maestras clarividentes y comprometidas como Marta Mata, representa la recuperación de la vieja idea de las Escuelas de Verano que tanta audiencia lograron en su día entre los maestros de Cataluña principalmente, aunque no solo. Desde 1965 hasta la muerte del dictador bajo el soporte de esa asociación se consolida en el ámbito catalán un grupo cada vez más numeroso de maestros (sobre todo mujeres) preocupados por la mejora y renovación de la práctica escolar, y cada vez más próxima al nacionalismo. Pero para el conjunto de grupos de la España progresista que busca una pedagogía renovadora es un referente imprescindible.

Para el conocimiento de la marcha real de muchos de estos MRP, además de los trabajos ya citados, es imprescindible adentrarse en las colecciones de varias revistas, que desde 1975 hasta nosotros suelen mostrarse próximas a planteamientos pedagógicos renovadores, como pueden significar Revista de Educación, Historia de la Educación, Educació $i$ Història y de forma especial Cuadernos de Pedagogía. No obstante, la nómina de cabeceras que acogen artículos relacionados directamente con los MRP es mucho más extensa4. Son publicaciones muy diferentes entre sí, pero en lo relativo al tema que nos ocupa algunas desempeñan una función difusora imprescindible, sobre todo informativa, mientras otras ofrecen artículos más reflexivos y extensos. Todas estas colaboraciones tienen sentido y son necesarias para comprender bien la contribución de cada uno de los MRP o de su conjunto.

Parece oportuno realizar un repaso sobre los MRP en las diferentes comunidades autónomas (CC. AA.), para poder alcanzar una valoración más precisa de este auténtico gran movimiento de renovación pedagógica. Y lo hacemos a partir del informe que en 1983 presenta la revista Vida Escolar sobre los MRP de cada CC. AA. Fue una tarea atractiva y necesaria para poder avanzar, en cuya elaboración tuvimos la fortuna de participar, al menos en parte. Allí se presenta el informe en

4 Además de las mencionadas, es imprescindible hacerlo también con otras editadas en Cataluña (Perspectiva Escolar, Temps d'Educació, Guix, Reforma de la Escuela, Aula de Innovación Educativa) y también en el conjunto de España: Tabanque (Escuela U. de Palencia), Colaboración y Kikiriki (Movimiento Freinet), Acción Educativa (Acción Educativa Madrid), Tendencias Pedagógicas (U. Autónoma de Madrid), Participación Educativa (Consejo Escolar del Estado), Revista Interuniversitaria de Formación del Profesorado (U. Zaragoza, Asociación Universitaria de Formación del Profesorado, continuadora de la histórica Revista de Escuelas Normales, que fue suprimida en 1936), Revista Galega de Educación, Campo Abierto (U. Extremadura), Aula. Revista de Pedagogía de la Universidad de Salamanca, Germinal: Revista de Estudios Libertarios, Con-Ciencia social: Anuario de Didáctica de la Geografía, la Historia y las Ciencias Sociales (Grupo Fedicaria). 
LOS MOVIMIENTOS DE RENOVACIÓN PEDAGÓGICA (MRP) EN LA ESPAÑA

DE LA TRANSICIÓN EDUCATIVA (I97O-I985)

JOSÉ MARÍA HERNÁNDEZ DÍAZ

el orden alfabético que ocupa cada CC. AA., pero ahora adoptamos algunas variantes, con el objeto de ofrecer al lector una comprensión más génetica de lo acontecido con los MRP en los años de este estudio (I970-I985). Esto significa también que el tratamiento a cada caso no será lineal ni uniforme en su formato.

Para el estudio y devenir de los MRP en Cataluña es previo considerar el significado de la Asociación de Maestros Rosa Sensat, nacida en 1965, por la confluencia de intereses de varios grupos de maestros con procedencia ideológica muy plural (cristianos, socialistas, nacionalistas y republicanos discretos)' y la especial contribución de Marta Mata al impulso de otros grupos de renovación pedagógica en el contexto catalán inmediato, además de la trascendencia innovadora y reconocimiento de su autoridad pedagógica y moral en el conjunto de España ${ }^{6}$. La personalidad y prestigio pedagógico de Alexandre Galí y de Artur Martorell, figuras destacadas de la renovación pedagógica catalana que enlazan con iniciativas anteriores a la guerra, enriquecen el proyecto inicial al prestar su apoyo y legitimidad.

Será casi por sinergia con el referente de la Escola d'Estiu de Rosa Sensat lo que explica qué ocurre en Cataluña, desde una propuesta nacionalista. En varias ciudades y comarcas de esta comunidad autónoma se van a ir organizando actividades formativas, escolas d'estiu y grupos de renovación pedagógica, alcanzando niveles elevados de participación entre maestros, principalmente, y profesores de otros niveles de enseñanza. En ese año de i983, además de Rosa Sensat y el MCEP, funcionan en Cataluña otros 17 colectivos pedagógicos de ámbito local o comarcal, MRP con diferentes denominaciones, procedencias y ubicaciones ${ }^{7}$.

La Asociació de Mestres Rosa Sensat tiene sedes en Barcelona, l'Hospitalet y Palma de Mallorca, desde donde impulsan sus actividades de formación de maestros, siempre desde una decidida apuesta catalanista y de pedagogía activa. Publica desde 1974, en catalán y mensual, la revista Perspectiva Escolar, que se convierte en referente principal del catalanismo pedagógico moderado y renovador. Pero más allá de su territorio próximo de actuación, la asociación Rosa Sensat se va a erigir, a través de la Escola d'Estiu celebrada en Barcelona, en enclave

Cfr. Codina I Mir, María Teresa: «Rosa Sensat y los orígenes de los MrP», Historia de la Educación. Revista Interuniversitaria, 2I (2002), pp. 9I-IO; GonZÁlEZ-AgÀPITO, Josep: Rosa Sensat $i$ Vila. Fer de la vida escolá, Barcelona, Rosa Sensat/Edicions 62, 1989; Monés y Pujol Busquets, Jordi: Els primers quinze anys de Rosa Sensat, Barcelona, Rosa Sensat/Edicions 62, I98I.

6 Cfr. Consejo Escolar del Estado: «Marta Mata i Garriga», Participación Educativa. Revista Cuatrimestral del Consejo Escolar del Estado, número extraordinario (mayo de 2007), p. 143.

Nos referimos a «Mestres de las Terres de l'Ebre» (Tortosa), «Mestres del Beguerdá» (Berga), «Moviment de Mestres de l'Alt Empordá» (Figueras), «Escola d'Estiu de les comarques gironines» (Gerona), «Casal del Mestre de Granollers» (Granollers), «Grup de Mestres de l’Anoia» (Igualada), «Grup de Mestres de Lleida» (Lérida), «Grup de Mestres del Bagés» (Manresa), «Moviment Educatiu del Maresme» (Mataró), «Grup de Enseyniantes de la Garrrotxa» (Olot), «Moviment de Mestres del Ripollés» (Ripoll), «Grup de Mestres del Penedés» (Sant Quintí de Mediona-Barcelona), «Equip de Mestres de Santa Coloma» (Santa Coloma de Gramanet), "Grup de Mestres de la Seu d'Urgell» (Seu d'Urgell-Lérida), «Grup de Mestres del Camp de Tarragona» (Tarragona), «Escola de Mestres Alexandre Galí» (Tarrasa), «Moviment de Mestres de la Val del Ges» (Tovello-Barcelona). 
multitudinario de referencia para el progresismo pedagógico y antifranquista de toda España antes de 1975; se convertirá en meca, en mítico punto obligado de paso y contacto para los nacientes MRP. Si en 1966 contó con la participación de 140 asistentes, en 1977 lo fueron 7869 (muchos de ellos procedentes de toda España), situándose en torno a los 5000 en esos años, y poco después declinando en cursos y participantes. Algunos de los temas centrales abordados se sitúan en torno a la discusión del documento «Per una nova escola pública catalana» (años I975 y 1976). Rosa Sensat es además centro de documentación pedagógica, biblioteca especializada, con capacidad de ofrecer asesoría psicopedagógica, por la escuela catalana y de sociología y política educativa. Articula un sistema jerárquico y casi profesional propio de una asociación muy organizada, a diferencia de lo que sucede en la mayoría de los MRP que adoptan un formato asambleario. Finalmente, la asociación Rosa Sensat participa en los Encuentros Estatales que se celebran de forma periódica (el primero en Almagro, Ciudad Real, 1979), pero también en los específicos que se organizan en Cataluña.

Los grupos de maestros Freinet recuperan en 1965 la tradición de pedagogía cooperativa y popular ya asentada en España desde mediados de los años I920, pero interrumpida por la guerra, con el apoyo de maestros franceses seguidores de la pedagogía popular freinetiana ${ }^{8}$. Crean ACIEs (Asociación para la Correspondencia y la Imprenta Escolar), nombre adoptado en la clandestinidad para evitar la represión franquista y para intercambiar sus experiencias de educación cooperativa. Ya con la democracia, en el congreso celebrado en Granada en 1977, deciden convertirse en Movimiento Cooperativo de Escuela Popular'. En 1983 tiene conformados y distribuidos por toda España grupos territoriales de maestros muy activos en Andalucía, Aragón, Asturias, Islas Baleares, Canarias, Cantabria, Castilla y León, Castilla-La Mancha, Cataluña, Extremadura, Galicia, Madrid, Murcia, La Rioja, Valencia, aunque no tenemos constancia de su existencia de Ceuta y Melilla.

El MCEP es tal vez la mejor expresión de los gérmenes de varios MRP concebidos como grupos abiertos, progresistas, democráticos, asamblearios, defensores de una educación pública y popular, en ámbitos rurales y urbanos, a través de la acción educativa cotidiana de sus maestros. Los Grupos Territoriales (GT) son la semilla fértil que se implanta con éxito en muchos lugares y escuelas, no exento de rebeldía y confrontación, frente a la pedagogía oficialista y la política educativa conservadora contra la que hay que confrontar durante estos años de transición

La figura de Ferrán Zurriaga, maestro de Valencia, es aquí decisiva.

9 Cfr. Groves, Tamar: «Freinet y los maestros españoles: La configuración de un movimiento social y pedagógico (1967-1983)», Educació i Història. Revista d'Història de l'Educació, 30 (2017), pp. I33-I44; GROvES, Tamar: «Maestros comprometidos: el movimiento Freinet durante el tardofranquismo y la transición a la democracia en España», en HeRnÁNDEZ, José María: Influencias francesas en la educación española e iberoamericana (I808-2008), Salamanca (2008), pp. 67-79; Hernández Huerta, José Luis y Gómez Sánchez, Alba: «Debating education and political reform. The Freinet movement and democratisation in Spain (1975-1982)", Historia da Educação, 20, 49 (2016), pp. 95-122; OrgAz, Aniceto: «El MCEP y la renovación en la comarca de Béjar», Estudios Bejaranos, I3 (2009), pp. 9I-Io8. 
LOS MOVIMIENTOS DE RENOVACIÓN PEDAGÓGICA (MRP) EN LA ESPAÑA

DE LA TRANSICIÓN EDUCATIVA (I970-I985)

JOSÉ MARÍA HERNÁNDEZ DÍAZ

educativa. Pero son también alternativa visible de un proyecto de escuela viva, enraizada en el entorno, popular, asamblearia y democrática, que trasciende los muros escolares para intentar cambiar la sociedad donde se inserta, con un compromiso firme y decidido por parte de sus miembros en la lucha por la democracia, precisamente en una etapa en la que había que crearla y afianzarla, en la sociedad y la vida pública, y por supuesto en la escuela. El MCEP forma parte de la FIMEM (Federación Internacional de Movimientos de Escuela Moderna), presente en muchos países para promover la pedagogía freinetiana, sus técnicas escolares, su concepto de escuela cooperativa y popular ${ }^{10}$, y publica en estos años que ahora estudiamos la revista Colaboración ${ }^{\text {II }}$, y más tarde la titulada Kikiriki. La estructura organizativa es desde el comienzo federal y asamblearia, y como expresión de ello la secretaría del MCEP por esos años ha estado ubicada de forma rotatoria en diferentes GT (Granada, Salamanca, Cantabria, Madrid, y así continúa). Conviene advertir, finalmente, que el MCEP es el único grupo/movimiento con implantación generalizada y con carácter de Estado, a diferencia de todos los demás, como vamos a ver.

En Andalucía funciona en 1983 de manera activa el MCEP en diferentes Grupos Territoriales (Málaga, Sanlúcar de Barrameda, Almería, Jaén, Huelva, Granada), y representa desde 1975 , como en otras provincias y regiones españolas, el soporte inicial y principal del nacimiento de los MRP al filo del final del franquismo, si exceptuamos el caso de Rosa Sensat. Así vemos que desde Málaga se pone en marcha el Colectivo Andaluz de Pedagogía Popular (CAPP), «impulsor de una pedagogía crítica, en una escuela activa, autogestionada, pública y andaluza», se reconoce así. Celebran la primera Escuela de Verano de Sevilla en Alcalá de Guadaíra, en 1979, de donde nace su lema: «Una escuela popular para una Andalucía nueva». Desde ahí van a celebrarse numerosos seminarios, jornadas, conferencias, escuela de verano y de invierno, ya de forma permanente, y desde i98I editan la revista Escuela 8I, de carácter bimensual. Forman parte de la coordinadora andaluza de MRP, en formato Federación de MRP, en la que también participa el CREA («Colectivo para la Renovación Educativa de Andalucía»), colectivo educativo, abierto, pluralista y democrático, con sede en Málaga. Así mismo, desde Córdoba hay que mencionar la actividad que mantiene por esas fechas la Asociación

1o Además de los ya citados, algunos de los muchos trabajos que se han publicado sobre el movimiento Freinet de estos años en España son ZurRiaga i Agustí, Ferrán: «Parlem de la formació permanent de l'ofici de mestre i de les idees del Moviment Freinet», Educació $i$ Història. Revista d'Història de l'Educació, 29 (20I7), pp. 20I-218; Zurriaga i Agustí, Ferrán: «La segunda época de la experiencia Freinet en España», en MCEP (ed.): La Escuela Moderna en España. Movimiento Cooperativo de Escuela Popular, Bilbao, Zero-Zyx, I979, pp. 76-In2; Ramos I GonzÁlez, Alfred: «La revista "Escola", òrgan del freinetisme valencià (1965-1969)", Educació i Història. Revista d'Història de l'Educació, 29 (2017), pp. I25-150; Ferraz Lorenzo, Manuel: «La segunda época de cooperación, experimentación y aplicación de las técnicas Freinet en las Islas Canarias (1977-1982)», Educació $i$ Història. Revista d'Història de l'Educació, 29 (2017), pp. I5I-170.

" Hernández Díaz, José María: "Colaboración (1976-1983). Revista Freinet de crítica y renovación pedagógica en la transición española del franquismo a la democracia», en IsCHE 36: Education, war and peace. Abstracts. London, Institute of Education, University of London, 20I4, pp. 136-138. 
de Antiguos Alumnos de la Escuela del Profesorado. En Melilla se organiza en 1983 la primera Escuela de Verano, por el Colectivo de Renovación Educativa de Melilla, con Ángeles Antelo como principal impulsora, y con el apoyo de maestros entusiastas procedentes de Málaga.

La Escuela de Verano de Aragón (EVA) nace en el año 1977, por influencia de grupos que se reúnen con anterioridad (Colectivo de los Martes, por ejemplo), del Colegio de Doctores y Licenciados de Zaragoza, y observando experiencias ya cuajadas de Rosa Sensat y Acción Educativa, según explican. Editan en 1980 la revista Al Rebullón, y organizan en Daroca el II Encuentro Estatal de MRP. Buscan preparar y mejorar a los docentes para una mayor proyección sobre los problemas educativos del contexto. En Aragón, además del grupo impulsor de la EVA tiene vida otro grupo de renovación activa, «Aula Libre»"

En Asturias, además del MCEP, tiene actividad el Colectivo Pedagógico de Asturias, que nace en 1976 a partir de la Asociación de Antiguos Alumnos de Magisterio. Organiza las Semanas Pedagógicas de Asturias (equivalente a una escuela de verano), ofrece cursos y seminarios alternativos sobre la escuela pública, la escuela rural, la escuela en su contexto asturiano. Comienzan a editar en el verano de 1980 la revista Andecha Pedagógica, dirigida por Martín Rodríguez Rojo, para reforzar lazos y aunar voluntades en pro de una escuela popular en Asturias.

En Baleares se cuenta con una extensión de Rosa Sensat desde antes de 1975, y desde ella tiene vida la Escola d'Estiu de Mallorca que ya se celebra a partir de 1977. Como sucede en Menorca con la «Escola per a Ensenyantes» que inicia sus actividades en 1978 .

En Canarias, además del MCEP, hay que reseñar desde 1978 la actividad del Colectivo de la Escuela de Verano de Canarias (en La Laguna) y el Colectivo de Enseñantes Canarios (Las Palmas de Gran Canaria), si bien ya con algunos años de anterioridad varios grupos de profesores han sentido la necesidad de organizar actividades formativas desde una lectura crítica de la pedagogía del aula. Todos propugnan una nueva escuela canaria.

El movimiento de enseñantes de Castilla y León comienza a configurarse hacia 1974, por la influencia inicial que despierta ACIEs (Asociación para la Correspondencia y la Imprenta Escolar), propia de la pedagogía Freinet, entre grupos de maestros preocupados por el cambio real en la enseñanza. Muy poco después, en 1975, aún en clandestinidad, comienzan a confluir con los grupos Freinet otros sectores de profesores procedentes de los Colegios Familiares Rurales de toda la región, y grupos de profesores no numerarios de las universidades de Salamanca y Valladolid. Se celebran los primeros Encuentros de Enseñantes en diferentes ciudades (el primero en Salamanca en 1977), con un carácter ya de movimiento amplio de enseñantes, y se formaliza como Asociación Pedagógica Concejo Educativo de Castilla y León en 1979. La organización de diferentes Escuelas de

Cfr. Lorenzo Lacruz, Juan: «Renovación pedagógica en Aragón. Estudio del caso del movimiento de renovación pedagógica "Aula Libre” entre 1975 y 20I2", Tendencias Pedagógicas, 27 (20I6), pp. 20I-230. 
LOS MOVIMIENTOS DE RENOVACIÓN PEDAGÓGICA (MRP) EN LA ESPAÑA

DE LA TRANSICIÓN EDUCATIVA (I970-I985)

JOSÉ MARÍA HERNÁNDEZ DÍAZ

Verano de Castilla y León desde la primera en 1978 (Salamanca), y con carácter anual y rotatorio en otras ciudades-capitales de provincia de la región, con la participación durante una semana de centenares, incluso miles de profesores, en actividades formativas, lúdicas, reivindicativas, musicales, refleja pautas pedagógicas autónomas, asamblearias en las que participan profesores que defienden la democracia en la sociedad y en la escuela. Así se funciona, hasta bien avanzados los años 1990, cuando en realidad Concejo Educativo va quedando reducido, hasta hoy, a ser un grupo de renovación pedagógica, activo pero muy mermado de componentes y también de iniciativas y proyectos ${ }^{13}$. Además del MCEP en algunas provincias (León, Salamanca, Ávila, Segovia, Valladolid, Palencia, Soria), en León funciona ADARGA -asociación de la escuela de verano de León-, y recordemos que el Movimiento de Educadores Milanianos tiene su origen y sede en Salamanca.

En Castilla-La Mancha tienen vida en 1983 el Colectivo Escuela de Verano de Albacete y el Colectivo Pedagógico de Alcázar de San Juan, además del MCEP. Todos ellos aúnan fuerzas de maestros progresistas que simpatizan con el movimiento de renovación educativa que se desarrolla en sectores docentes por toda España.

En Extremadura, además del MCEP, funciona la «Escuela de Verano de Extremadura» desde la primera convocatoria celebrada en Jaraíz de la Vera en 1976, seguida de las siguientes en Piornal. Existían en Extremadura experiencias pedagógicas renovadoras, como la Escuela de Orellana o la de Fregenal de la Sierra, si bien el movimiento educativo extremeño se inscribe con preferencia en el proyecto asociativo presindical de izquierdas del momento. Será en i980 cuando se legaliza el colectivo, que se autopostula como «abierto, independiente, pluralista y defensor de la escuela pública», para organizar seminarios, conferencias, debates, jornadas y otras Escuelas de Verano, y pasa a denominarse «Asociación Pedagógica de la Escuela de Verano de Extremadura».

Según la información oficial disponible en 1983, además del MCEP, funcionan en Galicia los siguientes MRP: Asociación Socio-Pedagógica Gallega (AS-PG) (nace en 1978) y la Escuela de Verano de Galicia, que entonces va por su cuarta edición, pues se inicia en I979, así como otras experiencias como «Preescolar na casa» (I977) y «Escola aberta» (1978) ${ }^{14}$. Advirtamos que la asociación pedagógica «Nova Escola Galega» nace precisamente en 1983. La As-PG es la responsable de

${ }^{13}$ Cfr. Hernández Díaz, José María: «La renovación pedagógica en Castilla y León (19701983)», en Hernández Díaz, José María; Grande Rodríguez, Miguel e Infestas Gil, Ángel: La educación en Castilla y León, Valladolid, Ámbito ediciones, 1983, pp. I55-192; Esteban Frades, Santiago: «Estudio de un grupo social de renovación pedagógica: El Movimiento de Enseñantes en Castilla y León. Concejo Educativo", Historia de la Educación. Revista Interuniversitaria, I4-Is (1995-96), pp. 433-452; Aragón SAlinas, Miguel Ángel: «Los MrPs, su sentido y sus formas de actuación. El caso de Concejo Educativo de Castilla y León», Tabanque. Revista Pedagógica, I7 (2003), pp. 87-98; Groves, Tamar: «El maestro rural como agente de cultura alternativa durante la transición española: El caso de la provincia de Salamanca», Aula. Revista de Pedagogía de la Universidad de Salamanca, I7 (20II), pp. I33- I43.

${ }^{14} \mathrm{Cfr}$. Costa Rico, Antón: «A escola que mudou: dinámicas, innovacions e experiencias na educación en Galicia (196I-2000)", Sarmiento. Anuario galego de historia da educación, II (2007), pp. 7-36. 
la organización de las Jornadas do Ensino de Galiza, desde 1976, y de la Escuela de Verano, así como de otros seminarios, cursos de actualización, conferencias y la publicación de la revista $O$ Ensino y otros materiales de apoyo para maestros y profesores. Sus objetivos principales explícitos son: trabajar por la normalización de la lengua y la cultura gallegas, integrar la escuela en el entorno y procurar que las actividades de los docentes tengan acento científico y metodología activa y moderna.

«Acción Educativa», el GT del MCEP y la «Escuela de Verano de Getafe» representan lo más significativo de los MRP en la Comunidad de Madrid para la fecha de referencia que ahora utilizamos, y cada uno manteniendo sus supuestos y organización, que a veces son confluyentes y en otras ocasiones mantienen su identidad y autonomía desde sus inicios y hasta nuestros días ${ }^{15}$.

«Acción Educativa» reconoce que su modelo procede directamente de varias fuentes: la tradición de la Institución Libre de Enseñanza, las experiencias pedagógicas desarrolladas en varias ciudades del norte de Italia (Rodari, Alfieri, Rodi, Tonucci, por ejemplo) y de Rosa Sensat y la Escola d'Estiu de Barcelona, cuando comienzan sus actividades en septiembre de 1976, si bien excluyen cualquier connotación nacionalista. La orientación pedagógica de «Acción Educativa» es muy heterogénea por entonces, aunque siempre desde un estilo abierto a las prácticas educativas de la Escuela Nueva, desde Montessori a Freinet, pasando por Piaget o Vigotsky. Y en su dimensión política «Acción Educativa» se mueve desde sus comienzos en la referencia de la famosa «Alternativa para la escuela pública», que identifica las posiciones educativas de izquierda en toda la etapa de la transición, aunque parece que próxima al PSOE de entonces. Defensa de la escuela pública, fomento de la pedagogía activa y la renovación pedagógica, defensa de una educación no elitista y respeto al pluralismo ideológico dentro de este marco son las claves que orientan sus actividades. De los primeros 500 participantes en la Escuela de Verano de Acción Educativa de 1976 a los 3500 de la de 1983 se da un salto cuantitativo (indican que hasta 1983 han pasado por sus actividades más de 13.000 profesionales), pero igualmente en el número y tipología de los cursos y seminarios ofertados a los docentes de la Comunidad de Madrid. También recibe colaboración de los ICE de las dos universidades públicas de Madrid entonces funcionando, la UCM y la UAM. Desde sus comienzos edita el boletín-revista Acción Educativa, junto a otras publicaciones, y hoy continúa organizando de forma ininterrumpida la Escuela de Verano de Madrid (va por la edición 43), además de otras actividades formativas.

El Colectivo de la Escuela de Verano de Getafe, nacido en 1980, «Se configura [dicen ellos en su informe de 1983], como un grupo de personas no dependientes de instituciones públicas ni entidades políticas. Abierto a la renovación y al cambio del sistema educativo. Partidario de la escuela pública, entendiendo ésta como una comunidad abierta de alumnos, maestros y padres que, integrada en su

is Cfr. Pinto Delgado, José María: Los mrps de la Comunidad de Madrid. Análisis de sus influencias en el desarrollo profesional docente, tesis doctoral presentada en la Universidad de Valladolid en 2016. Dirigida por Luis Torrego y José Luis Parejo. 
LOS MOVIMIENTOS DE RENOVACIÓN PEDAGÓGICA (MRP) EN LA ESPAÑA

DE LA TRANSICIÓN EDUCATIVA (I970-I985)

JOSÉ MARÍA HERNÁNDEZ DÍAZ

contexto social, posea una acción liberadora y facilite el desarrollo de actitudes críticas, libres y creativas». El trabajo de Julio Rogero, uno de sus promotores y líderes más destacados, hace balance de su trayectoria y del presente en el contexto de los MRP, no habiendo renunciado a ninguno de sus presupuestos ideológicos y pedagógicos, y manteniendo actividades y seminarios formativos para profesores desde una visión crítica y asamblearia en defensa de la escuela pública ${ }^{16}$.

Murcia cuenta en aquellas fechas con GT del MCEP y el movimiento de Escuela de Verano aparece en la región murciana en el año 1978. A partir de ahí van a promoverse numerosas actividades formativas de orientación pedagógica renovadora.

En el País Vasco, además del MCEP, desarrollan actividades la asociación pedagógica Adarra (que organiza cursos de verano en 1977 principalmente para las escuelas públicas, poco después de haberse creado, siendo Luis Otano uno de sus líderes), Gordailu (asociación de profesores de las ikastolas que está organizada desde i968), la Asociación Psicopedagógica de Bergara y otros organismos como los ICE de Deusto y de la Universidad del País Vasco ${ }^{17}$. Desde mediados de los años ochenta decrece la participación en el colectivo Adarra, sobre todo a partir de la oferta de cursos y actividades procedentes de la Consejería de Educación del gobierno vasco.

De Navarra no disponemos de información para esas fechas de 1983, aunque se deduce la carencia de grupos de renovación pedagógica.

En La Rioja funciona el «Colectivo de Renovación Pedagógica de La Rioja, EVERI, Escuela de Verano de La Rioja», que inicia su actividad en el verano de I980, contando con la participación de I50 personas. El principal soporte lo recibe del Sindicato de Trabajadores de la Enseñanza (STE) en infraestructura y colaboración de participantes.

En las diferentes provincias del País Valenciano/Comunidad Valenciana, además del MCEP, mantienen actividad otros colectivos pedagógicos renovadores, que organizan la primera Escuela de Verano en 1976, después de varios intentos y prohibiciones del Gobierno Civil. Se adhieren también sectores de antiguos alumnos de la Normal, del Colegio de Doctores y Licenciados de Valencia, el Sindicato de Enseñantes, y más tarde el ICE de la Universidad de Valencia y otros organismos relacionados con la formación de profesores, como viene ocurriendo con otros MRP en varias CC. AA. ${ }^{18}$.

16 Cfr. Rogero Anaya, Julio: «mrps y profesionalización docente», Revista Latinoamericana de Educación Inclusiva, 4, I (20IO), pp. I4I-I66.

${ }_{17} C f r$. Dávila Balsera, Paulí: «La Renovación pedagógica en el País Vasco: segunda mitad del siglo Xx». Sarmiento. Anuario Galego de Historia de la Educación, 9 (2005), pp. 85-IO4; DÁvila BALSERA, Paulí (coord.): El profesorado y la renovación pedagógica en el País Vasco, Madrid, Delta, 20I8, p. 2is; Delgado Cendagortagalarza, Ander: «Gordailu y la renovación pedagógica en el País Vasco. Política y educación en el tardofranquismo", Aula: Revista de Pedagogía de la Universidad de Salamanca, 22 (2016), pp. 189-203.

18 En 1983 tomamos nota de Escola d'Estiu del Pais Valenciá (Valencia), Collectiu de Mestres de la Plana (Castellón de la Plana), Escola d’Estiu del Pais Valenciá (Elche, Alicante), Colectivo de Maestros de la Marina Alta (Denia, Alicante). Ver también Molina Galván, María Dolores: La práctica viva y experiencia colectiva de la renovación pedagógica: historia de vida del MRP del País Valenciá Gonçal Anaya, Valencia, Universitat de Valencia, $20 I I$. 
LOS MOVIMIENTOS DE RENOVACIÓN PEDAGÓGICA (MRP) EN LA ESPAÑA

DE LA TRANSICIÓN EDUCATIVA (I970-I985)

JOSÉ MARÍA HERNÁNDEZ DÍAZ

El Movimiento de Educadores Milanianos (MEM), compuesto por maestros y educadores que siguen las propuestas de Lorenzo Milani, sacerdote y maestro de la famosa Escuela de Barbiana, de donde emerge "Carta a una maestra», obra crítica (aparecida en 1967) sobre el sistema educativo italiano y el modelo occidental de escuela, de tanto impacto en el mundo latino desde los años 1970, tiene rasgos comunes a los MRP mencionados hasta ahora y también algunas diferencias. José Luis Corzo ${ }^{19}$, escolapio, fue el impulsor inicial del MEM y hoy (2018) continúa animando su actividad y publicaciones, entre las que cabe destacar la revista Educar(nos), que en la actualidad lleva publicados 84 números de singular interés para comprender las experiencias educativas que llevan a cabo sus miembros, así como los debates y planteamientos pedagógicos de fondo sobre la educación. El MEM está conformado por maestros y educadores que ejercen en centros escolares públicos y concertados, pero muchos se sitúan más en el ámbito de la pedagogía social, en centros de acogida y/o reeducación de menores, con frecuencia de procedencia social humilde, muchos de familias emigrantes; colaboran con el Tribunal Tutelar de Menores, o trabajan en centros de formación profesional agraria (como es el caso de la Granja Escuela Lorenzo Milani, ubicada en Salamanca). La orientación ideológica de sus miembros es explícitamente progresista, defensora de la escuela pública (que responde no exactamente a la identificación con estatal), y muchos de ellos de decidida confesión cristiana y de compromiso próximo al de la teología y la pedagogía de la liberación (Paulo Freire es uno de sus referentes obligados). Lo decimos así, pero con la conciencia de que su punto de partida, Lorenzo Milani, difícilmente podría ser encasillado en una determinada corriente. Los componentes del MEM, ya en los años de transición que nos ocupan, aparecen al lado de otros grupos y MRP, en los espacios colectivos de encuentro pedagógico, pero siempre con sus indudables señas de identidad. Nos recuerdan que es en I98I cuando se celebra en Salamanca el Primer Encuentro Español de Educadores Milanianos, en el que se decide su legalización. En el ya citado informe de 1983, de Vida Escolar, nos indica su fundador: «Las relaciones del MEM con la administración anterior (UCD) han sido burocráticas. Las relaciones con otros MRPs han sido muy buenas y hemos colaborado con ellos en Escuelas de Verano y otros cursillos, aunque los "enseñantes" suelen considerar la Escuela de Barbiana, y supongo que al MEM, como algo demasiado exigente $»^{20}$.

19 Es ya abundante la literatura científica que se ha ocupado de Lorenzo Milani y del MEM, pero por no resultar sobreabundantes, remitimos a algunos trabajos de proximidad, cuando el MEM también se encuentra en fase constituyente, $c f r$. Corzo Toral, José Luis: «Nuestra aportación al xx aniversario de Milani», Cuadernos de Pedagogía, I54 (1987), pp. 89-9I; Corzo Toral, José Luis: «Balance en el xx aniversario de Lorenzo Milani y la "Carta a una maestra" ", Historia de la Educación. Revista Interuniversitaria, 6 (1987), pp. 341-352.

${ }^{20}$ Cfr. Vida Escolar, 223 (1983) p. 68. 
LOS MOVIMIENTOS DE RENOVACIÓN PEDAGÓGICA (MRP) EN LA ESPAÑA

DE LA TRANSICIÓN EDUCATIVA (I970-I985)

JOSÉ MARÍA HERNÁNDEZ DÍAZ

\section{Las señas de identidad de los MRP en sus años de esplendor}

Acabamos de ofrecer un repaso muy resumido sobre el origen y primeros pasos de los MRP, que nos permite también identificar los años más espectaculares en su vida real (1977-1983), en términos braudelianos un ciclo corto, una coyuntura.

Más allá de las diferencias que existen entre ellos, por razones geográficas, culturales, lingüísticas, matices políticos, número de miembros que los componen, trayectoria histórica vivida, diferente peso de la carga utópica presente en la mayoría de ellos, nos parece que existen algunas señas de identidad en las que coinciden la mayoría de los MRP del momento, que son expresión de la respuesta que ofrecen los colectivos de docentes al contexto sociopolítico que vive la España de la transición educativa. Por esto, cuando cambian algunas circunstancias sociopolíticas estructurales comienzan a modificarse las relaciones de estos colectivos pedagógicos con la vida cotidiana escolar, con el entorno donde se ubican y sobre todo con la nueva administración educativa. Esa es la tesis que compartimos con Gimeno Sacristán en su lúcido trabajo sobre el tema ${ }^{2 r}$. El contexto lo cambia todo en educación, y por ello nos atrevemos a decir que los MRP, como parte de los movimientos sociales de la transición, han dejado pronto de ser movimiento, para ser en la mayoría de los casos grupos de renovación pedagógica en los que participan los docentes menos desencantados o no tan integrados en el sistema educativo oficial o en la administración.

Los MrP que estudiamos, para esa etapa, adoptan una modalidad de colectivo, poco organizado, con frecuencia asambleario, al menos hasta avanzado el año 1983, cuando se exige que todos los grupos que desean recibir la subvención que ofrece el MEC han de estar legalizados formalmente. La composición del colectivo es muy heterogénea en su procedencia, pues aunque la mayoría del grupo está formada por maestros también se incorporan profesores de segunda enseñanza y universidad, y algunos estudiantes de magisterio y pedagogía. Igualmente conviene advertir la diferencia de compromiso y permanencia de quienes participan puntualmente (por ejemplo, en las Escuelas de Verano) respecto a otros líderes y socios que están al pie del cañón, y con mucha fortaleza durante años. Muchos compañeros de los MRP de la época, mayoritariamente mujeres, y maestras en particular, encuentran acogida en las actividades seminarios, manifestaciones, jornadas de convivencia que se organizan ${ }^{22}$ (con meriendas y conciertos de música alternativa, no solo de cantautor), lo que podríamos denominar espacios nuevos de sociabilidad para docentes muy habituados al rigor y disciplina de una inspección que no acaba de salir de los modos de hacer del franquismo.

En los MRP se combinan los encuentros de formación pedagógica alternativa frente a una formación de muy baja calidad recibida en las Escuelas Normales y en las facultades universitarias, con el intercambio de experiencias pedagógicas

${ }^{21} \quad C f r$. Gimeno SACRIstán, José: «El ayer y el hoy de la renovación pedagógica: la mutación del contexto", Cuadernos de Pedagogía, 232 (1995), pp. 8-13.

${ }_{22}$ Cfr. Alonso Ramírez, María de la Calle: «Los Movimientos de Renovación Pedagógica ¿espacios propios para las maestras?», Tabanque. Revista Pedagógica, 28 (2015), pp. 89-IIo. 
innovadoras, la recepción de lecturas de autores representativos de la innovación y la pedagogía crítica (Freinet, Freire, Baudelot, Carlos Lerena, Bourdieu, Piaget, Milani, Lodi, Tonucci, Rodari ${ }^{23}$, entre otros muchos), la incorporación de asuntos y campos pedagógicos novedosos por entonces (coeducación, educación inclusiva, educación para la paz, escuela rural, el papel de la mujer en la educación, la objeción de conciencia, la educación ambiental, la educación consumerista, las universidades populares, la enseñanza en lengua materna, la alfabetización de inmigrantes y otros muchos). Se piensa la educación y la escuela desde una lectura crítica y utópica, de la sociedad y de la escuela al mismo tiempo. ¿Quién podía sustraerse a la aspiración de la libertad y carga utópica necesaria después del oscurantismo impuesto por la larga dictadura franquista? Los MRP ejercen con frecuencia la función de catalizadores de los nuevos temas que emergen, afectan y preocupan a la sociedad y que merecen una respuesta educativa. Impulsan la renovación pedagógica en el centro escolar y en las aulas, pero no solamente ahí, también en la calle, en el entorno, en la comunidad rural, en el barrio, en la prensa, en circuitos culturales casi clandestinos.

Los MRP del momento son también espacio perfecto para el debate y la defensa pública de un proyecto de reforma educativa democrática, sobre todo si tenemos presente que aún no se había producido la legalización de los partidos políticos, o estos andaban trazando sus primeras estructuras visibles para participar en las convocatorias electorales de 1977 en adelante. Algo semejante conviene advertir de los sindicatos libres, que no lo son sino a partir de 1977. Es por ello tan decisivo el debate que se lleva a cabo en muchos MRP sobre documentos críticos y alternativos de izquierdas, frente a la política educativa oficial, elaborados en la Escola d'Estiu de Barcelona («Per una escola pública catalana», I975), por el Colegio de Doctores y Licenciados de Madrid («La alternativa para la enseñanza», 1976), y otras posteriores declaraciones y reivindicaciones de tipo político y sindical. El debate sobre la escuela pública y democrática es permanente en todos los MRP de estos años, y ahí participaban militantes de partidos y organizaciones políticas de izquierdas, muchos de ellos de clara procedencia anarquista y asamblearia, muchos originarios de grupos y comunidades cristianas de base de perfil obrerista, muchos docentes incipientes sindicalistas de STES, CC. OO., UGT, CNT. Estaban muy cerca los rescoldos del humeante mayo francés, de la lectura de Marcuse y de un marxismo renovado de tipo gramsciano, y algo más en lejanía los efectos de un Concilio Vaticano II por lo que supuso de «encarnación» en los ámbitos populares y de parte de sacerdotes, ex y cristianos comprometidos. También llegaban en masa propuestas de la pedagogía de la liberación latinoamericana. La renovación pedagógica no resultaba ajena a la social, que van juntas en los MRP, sin renunciar a la defensa de cambio profundo en la política educativa, en la defensa estructural de un nuevo tipo de sistema educativo de modelo de

${ }^{23} C f r$. Tort i Bardolet, Antoni y Pujol i Mongay, Maite: «Referents per a una nova escola democrática. La influencia de la pedagogía italiana en els col.lectius de Mestres durant la transició política a Catalunya i a Espanya", Educació i Història. Revista d'Història de l'Educació, 25 (2015), pp. $149-175$. 
LOS MOVIMIENTOS DE RENOVACIÓN PEDAGÓGICA (MRP) EN LA ESPAÑA

DE LA TRANSICIÓN EDUCATIVA (I970-I985)

JOSÉ MARÍA HERNÁNDEZ DÍAZ

centro escolar. De ahí que sea frecuente observar en estos sectores educativos, por entonces, que un maestro participe en un MRP, lo haga también en el movimiento vecinal de su barrio, en los incipientes escarceos sindicales de docentes, en un naciente partido político, en los grupos de estudio y renovación de su escuela o instituto. Se trataba casi de una opción totalizante y holística por el cambio social y al mismo tiempo el educativo. Por esto tal vez convenga hablar de forma más pertinente de movimientos sociales en el sector de la educación para referirnos a aquellos MRP de los años de la transición.

Finalmente hemos de mencionar un rasgo que define los MRP que nacen en una España que sale de una dictadura centralista, y que se abre a un modelo de Estado descentralizado a través de una Constitución (1978) que reconoce las CC. AA., con sus posteriores Estatutos de Autonomía y competencias también en educación. Nos referimos al perfil nacionalista que adoptan la mayoría de los MRP de la época, que siendo de izquierdas parecen contradecir la tradición conservadora que representa el nacionalismo, tal como piensa una autoridad reconocida en el tema, como es José Álvarez Junco ${ }^{24}$. Es indudable que la influencia inicial de Rosa Sensat y el nacionalismo catalán de todas las procedencias ideológicas van a incidir en el discurso político de la transición, y desde luego en los MRP del conjunto de España, pues en regiones donde no existía tradición nacionalista alguna parece producirse entonces un cierto embelesamiento nacionalista pedagógico impulsado desde sectores de la izquierda y con efecto real en muchas las actividades y declaraciones promovidas por los MRP. La defensa de la lengua propia fue una seña de identidad de todos los MRP ubicados en las CC. AA. que la poseían, porque había resultado ser un drama en la escuela franquista el olvido o la persecución de estas lenguas que ya eran cooficiales (gallego, euskera y catalán). Había que reparar con urgencia y ratificar la idoneidad de su uso en la escuela y en la vida cotidiana, allí donde fuera legítimo su uso.

\section{El abrazo del oso sobre los MRP (1983-1985)}

El fracaso del golpe de Estado de un grupo de militares fascistas, en febrero de 1981, significó la consolidación real en la calle de la democracia, pues la respuesta social de los ciudadanos españoles fue de apoyo masivo a la Constitución y a la democracia, como en ninguna otra ocasión de la reciente historia contemporánea de España se había producido. Pero seguramente será el triunfo del Psoe en

24 «La izquierda española, o al menos parte de ella, no ha sido la única pero sí una de las pocas que han evolucionado en sentido contrario. Porque, en lugar de intentar reforzar el Estado central, y el sentimiento comunitario que lo legitima, se alineó con los nacionalismos periféricos. Ocurrió ya entre algunos republicanos durante la Guerra Civil y se aceleró bajo el franquismo. Era comprensible, dado el ultraespañolismo de la dictadura y el peso del catalanismo y el vasquismo entre las mitologías movilizadoras de la oposición. Pero dejó de serlo tras la consolidación de la democracia y la integración en la Unión Europea». Álvarez Junco, José: «De una a otra izquierda», El País, 7 de enero de 20r8. De este mismo autor mencionamos para este tema su excelente obra Mater dolorosa. La idea de España en el siglo XIX, Madrid, Santillana, $200 I$. 
las elecciones generales de 29 de octubre de 1982 lo que represente en España el comienzo real de construcción de alternativas sociales, políticas, y también educativas, posibles y viables, a la endeble situación que la fragilidad de los gobiernos de UCD habían conducido a España. Precisamente, desde ese contexto general propio de la España que anda naciendo a un nuevo orden político, todavía de inseguridad democrática y de indefinición educativa, se comprende que los años de máxima explosión y visibilidad de los MRP sean sin duda los que van de 1978 a 1983 .

España estaba naciendo a un nuevo orden político, representado en un PSOE que ha renunciado al marxismo en I979, que se ha moderado, y que va a gobernar de forma ininterrumpida hasta 1995. Van a ser años claves también para el asentamiento de varias reformas educativas de claro tono socialdemócrata, con muchas luces y algunas sombras. Y en sus comienzos había que resolver un asunto pendiente para la educación española, como era sin duda alguna el protagonismo alcanzado por los MRP, muy difícil de controlar dado el carácter asambleario de las numerosas Escuelas de Verano, Encuentros de Enseñantes y de las muchas actividades promovidas por los grupos de renovación pedagógica en cualquier rincón de España.

A ello se añadía un notorio problema, bien conocido en los ambientes de base de maestros y profesores que apostaban por la renovación, como era que el PSOE carecía de un número suficiente de cuadros y militantes como para intentar controlar estos movimientos pedagógicos de base. A su vez, los militantes y cuadros propios del PCE, generalmente bien cualificados, que desde la clandestinidad venían interviniendo en cuestiones de enseñanza, pronto mostraron su debilidad en número suficiente como para intervenir en varios frentes a la vez: en la vida política a través de los canales parlamentarios y representativos (que ya en octubre de 1982 les mostró los límites de sus aspiraciones como partido), en la lucha sindical apenas incipiente canalizada a través de Cc. Oo., y en los grupos de renovación pedagógica, que en su inmensa mayoría se mostraban asamblearios y reticentes a cualquier dependencia política, partidista y jerárquica.

La estrategia del equipo de José María Maravall, al frente del Ministerio de Educación y Ciencia desde finales de 1982, fue desde luego muy lúcida para resolver la carencia de militantes cualificados en el sector de la enseñanza, capaces de liderar las reformas educativas que, sin embargo, el propio ministro sí tenía muy claras. Primero, pretendía nutrirse de cuadros docentes, de líderes entre maestros y profesores, desde los posibles caladeros que representaban los MRP y todas sus actividades de reforma pedagógica y de defensa de la escuela pública. El nuevo ministro de Educación precisaba de muchos y buenos líderes pedagógicos para la nueva administración educativa. Y en segundo lugar, necesitaba articular en la sociedad, en centros de primera y segunda enseñanza, un amplio sector de simpatizantes para impulsar y consolidar las reformas escolares en ciernes, que debían concluir en la aprobación de grandes leyes de educación al finalizar tal proceso constituyente en educación, como así fue finalmente con escasas variantes. 
LOS MOVIMIENTOS DE RENOVACIÓN PEDAGÓGICA (MRP) EN LA ESPAÑA

DE LA TRANSICIÓN EDUCATIVA (I970-I985)

JOSÉ MARÍA HERNÁNDEZ DÍAZ

La expresión de los límites de estos MRP se concreta en los pasos a seguir desde el Ministerio de José María Maravall entre 1983 y 1985 en lo que se refiere a la creciente integración de muchas de las iniciativas de los MRP en la nueva política educativa del gobierno socialista, y en especial en lo que se relaciona con la modernización y la innovación educativa.

Desde el primer momento en la nueva administración socialista se reconoce a los MRP como interlocutores preferentes de los asuntos de la perentoria modernización pedagógica que precisaba España. Los MRP pasaban en 1983 de haber sido perseguidos durante el franquismo, a ser tolerados durante los años cruciales de la transición, hasta ser adoptados como expresión propia de la política educativa socialista, al menos en algunas de las ideas menos radicales de estos grupos.

De ahí la importancia y el simbolismo de la celebración en febrero de 1983 en Salamanca del V Encuentro de $\mathrm{MRP}^{25}$, de todos los colectivos posibles y más importantes de España (en número próximo a los 50), coordinados por el MRP de Castilla y León, Concejo Educativo. Fueron sesiones de trabajo realmente espectaculares y esperanzadoras, que confirmaron la independencia inicial de los MRP, su autonomía y su capacidad de propuestas alternativas a las administraciones públicas, pero también la receptividad que provocaban entre los incipientes representantes del Ministerio de Educación. La presencia física del ministro de Educación, del mismo José María Maravall, al final del Encuentro, compartiendo menú escolar en la Escuela Hogar de Santa Marta de Tormes, a las afueras de la ciudad de Salamanca, con los líderes de los MRP de toda España, y pronunciando un discurso revelador marca un referente histórico. Este texto bien puede considerarse una pieza maestra del adelanto público y en contextos de base de la política educativa que estaba a punto de emprender el MEC para toda España, y en concreto para las nuevas relaciones con los MRP y su forma particular de abrazarlos. Es posible comentar ahora, cuando han transcurrido varias décadas desde aquel encuentro, que, para nosotros, la política diseñada por Maravall para los MRP se hizo con tanto cariño y calor que comenzaba a dejarlos sin respiración, hasta ahogarlos y fagocitarlos, aunque no fuera esa la única razón de su posterior desdibujamiento y en muchos casos desaparición ${ }^{26}$.

El discurso de Maravall en Salamanca, dirigido a los representantes de los MRP que por entonces aglutinaban (según cifras del propio ministro de Educación) a más de 30.000 profesores de todos los niveles docentes, planteó con inteligencia la acogida e integración de los MRP en la política educativa del PSOE, más allá de una colaboración bilateral, que también propuso. De esta forma, los MRP debían comenzar a sentirse como los principales compañeros de viaje del proyecto educativo del nuevo Gobierno socialista. Para ello propuso establecer comisiones de enlace permanente, acuerdos concretos de financiación de las actividades de los

25 Con anterioridad al Encuentro de Salamanca se habían celebrado Encuentros de MRP de toda España en Almagro (1979), Daroca (1980), Sevilla (I98I) y San Sebastián (1982).

${ }^{26} C f r$. Hernández Díaz, José María: «La renovación pedagógica en España al final de la transición. El encuentro de los MrP y el ministro Maravall (1983)», Educació i Història. Revista d'Història de l'Educació, I8 (20II), pp. 8I-IO5. 
MRP, remodelación de las revistas oficiales del MEC incorporando propuestas de base procedentes de los MRP, invitación a participar en los procesos de reforma e innovación pedagógica en todas las instancias oficiales y públicas orientadas a la formación de los profesores (mucho más allá de los entonces modelos vigentes, activados desde los ICE), y finalmente que el MEC financiara la organización de un nuevo Encuentro de MRP (mejor Primer Congreso) al finalizar el año 1983 en la ciudad de Barcelona, como así sucedió.

La estrategia trazada por el nuevo equipo del MEC, difundida por el ministro de Educación, José María Maravall, a los MRP en Salamanca se fue cumpliendo de manera puntual y eficaz en los meses que siguieron. Tomemos algunas muestras.

La revista Vida Escolar, que había nacido en el seno del CEDodep (Centro de Orientación y Documentación Didáctica de Enseñanza Primaria) -I958-, y se distribuía de forma gratuita a todos los centros escolares de España, con centenares de miles de ejemplares editados y difundidos, fue eliminada y sustituida a finales del año 1983 por Comunidad Escolar, más acorde en su orientación con los criterios del nuevo equipo ministerial de educación. No deja de ser simbólico y revelador que uno de los últimos números publicados por Vida Escolar, el 223 de I983, vaya destinado de forma monográfica a los MRP. Ahí se recogen referencias históricas de actualidad de aquel momento de los diferentes grupos existentes en cada una de las 17 comunidades autónomas, más Ceuta y Melilla, además de otros trabajos de encuadramiento. Tal vez este monográfico de Vida Escolar (1983) pudiera entenderse simbólicamente como una especie de canto del cisne, no solo de la propia revista, sino a corto plazo de algunos de los MRP y su progresiva disolución, sobre todo a partir de los años 1990. $\mathrm{O}$, al menos, claramente la disminución de su peso real como proyecto social colectivo, desde luego si los comparamos con el protagonismo que habían alcanzado a finales de los años i97o.

Otra de las novedades que anunciaba Maravall en ese discurso de clausura de los MRP en febrero de 1983 era la celebración de un nuevo Congreso de los MRP, en el que se estudiaran y concretaran mucho más y mejor las relaciones a establecer con el nuevo Ministerio de Educación. En efecto, en diciembre de 1983 se celebraba en Barcelona un nuevo Encuentro, que adoptaba el formato de Congreso constituyente de MRP, más formalizado e institucional, que buscaba oficializar la citada estrecha relación con la administración educativa, aunque guardando convenientemente las formas. Así se funcionó en aquella coyuntura, legitimando de una vez los oficios desempeñados durante años por los MRP en pro de la innovación educativa, la defensa de la escuela pública, el debate sobre la formación de los profesores y la construcción de espacios propios de sociabilidad de los «enseñantes», término utilizado con frecuencia por aquellas fechas para designar a los profesores.

Quisiéramos advertir que el proceso que vivieron los MRP en estos años que ahora valoramos fue siempre acompañado por dos tipos de colaboración.

Una fue la propia historia de las Escuelas de Verano, nacidas como Escolas d'Estiu en Barcelona en I9I4. La recuperación de esta tradición en 1966 por la Asociación de Mestres Rosa Sensat va a representar pocos años después un referente 
LOS MOVIMIENTOS DE RENOVACIÓN PEDAGÓGICA (MRP) EN LA ESPAÑA

DE LA TRANSICIÓN EDUCATIVA (I970-I985)

JOSÉ MARÍA HERNÁNDEZ DÍAZ

ineludible para miles de profesores de toda España, participantes en decenas de Escuelas de Verano y actividades de renovación pedagógica. No es casual por ello que en 1983 la Diputación de Barcelona publicara una edición facsímil de los programas de las primeras Escuelas de Verano de Barcelona (I9I4-I936), con motivo del I Congreso de Movimientos de Renovación Pedagógica, y tal ejemplar de libro se entregara a cada uno de los participantes ${ }^{27}$. Era una manera elegante de señalar los hitos de aquella historia colectiva de innovación pedagógica que gozaba de señas de identidad, que no eran otras que las de Cataluña y su tradición pedagógica renovadora. Y, desde luego, el merecido homenaje a figuras estelares del socialismo catalán como Marta Mata y su compromiso con la educación popular.

La segunda vía de apoyo y colaboración permanente estuvo representada por varias revistas nacidas en esta etapa de la transición, y apoyadas por MRP. Este es el caso de Colaboración, publicación periódica propia del Movimiento Cooperativo de Escuela Popular (los grupos Freinet), editada en Granada, y bien distribuida por todos los grupos territoriales freinetianos entre centenares de maestros. Pero mención aparte merece la revista Cuadernos de Pedagogía, nacida en 1975 en Barcelona, y dirigida en aquellas fechas por dos extraordinarios promotores de la educación pública renovadora, como fueron Fabrizio Caivano y Jaume Carbonell. Sin Cuadernos de Pedagogía no puede comprenderse bien la transición educativa y los grandes procesos de cambio y reforma educativa vividos en España en los últimos cuarenta años, y desde luego los procesos propios del nacimiento, madurez y posterior declive de los MRP, o su reducción real a grupos de renovación educativa.

Por tanto, y resumiendo, la perspectiva del tiempo histórico vivido y reflexionado nos invita a considerar que la influencia de la tradición pedagógica de $\mathrm{Ca}$ taluña sobre los MRP de toda España resultó decisiva para consolidar tantas y tan diversas modalidades de renovación pedagógica en la España de la transición. Pero no menos influencia tuvo el socialismo catalán en la conjunción de intereses del MEC y los MRP a la hora de diseñar nuevos programas de actuación sobre la educación de toda España desde una plataforma tan influyente y decisiva como la que representa un Ministerio de Educación. Maravall entendió perfectamente esta simbiosis catalana entre socialismo moderado y tradición pedagógica innovadora. En nuestra opinión, aquel I Congreso de Barcelona celebrado en 1983 es la mejor expresión del proceso de integración de los MRP en las políticas impulsadas desde el Gobierno central y el MEC ya de color socialista.

La incorporación progresiva de muchos cuadros y líderes de los MRP como responsables directos o complementarios de la estructura directiva y animadora de la nueva administración escolar socialista a partir de 1983, bien desde las Direcciones Provinciales de Educación, y desde la Consejería de Educación de algunas de las nacientes CC. AA., representa el inicio de la concreción realista de algunas políticas socialistas sobre renovación pedagógica, compartidas con los MRP. Pero al mismo

27 Diputació de Barcelona: Escola d'Estiu (I9I4-1936). Edició facsímil del programe i croniques, Barcelona, Diputació de Barcelona, 1983, 294 pp. 
tiempo expresa el inicio de la neutralización de posibles acciones de rebeldía política y/o pedagógica que pudieran ser emprendidas por líderes pedagógicos reconocidos dentro de los MRP, como era habitual algunos años atrás.

Por otra parte, entre 1983 y 1984 en el Ministerio de Educación se va fraguando la implantación de un modelo de formación permanente de los profesores más cercano a los interesados, como ya practicaban algunos MRP, menos formalista y teórico que el que llevaban a cabo los ICE de cada universidad, centros formadores muy cargados de ambigüedad pedagógica modernizadora y tecnocrática por su procedencia tardofranquista y poco controlables desde la administración educativa, aunque es cierto que en algunos ICE se había dado oportunidad a la colaboración con algunos $\mathrm{MRP}^{28}$. Además, cierta aversión de tono «populista» y «sindicalista» hacia lo que procede de la universidad, existente en algunos sectores influyentes del PSOE y de la UGT de aquel momento, como ocurría con los ICE, fue una circunstancia decisiva para que la nueva administración educativa del PSOE apostara por otros modelos de formación permanente. Eso es lo que representa el nacimiento de los Centros de Profesores (CEP) a finales de 1984, a cuya estructura oficial de gestión también se incorporan muchos componentes de los MRP. Quedaba así regularizada la presencia activa de muchos líderes pedagógicos procedentes de los MRP en la administración educativa socialista, coincidente al tiempo con la lenta, progresiva y definitiva desmovilización de muchos cuadros cualificados en el seno de los MrP.

Este conjunto de factores mencionados, junto al reconocimiento oficial de las actividades formativas de los MRP y diferentes grupos de renovación pedagógica, así como las ayudas y financiación oficial que se les facilita ${ }^{29}$, va a ir contribuyendo a una efectiva disolución e integración de muchos elementos activos de los MRP en las estructuras de la administración educativa socialista.

Al mismo tiempo que se producía el asentamiento democrático en el funcionamiento del sistema educativo con la implantación del programa educativo del PSOE, se estaba consumando el «abrazo del oso» entre la política educativa del Ministerio de Educación y las propuestas y reivindicaciones históricas de los MrP.

Estaba cambiando de forma explícita y acelerada el contexto socioeducativo de la España de los ochenta, con la aplicación del programa educativo del PsOE, pero también con la contraofensiva en la calle de sectores involucionistas. El resultado parcial de tales tensiones lo encontramos en la LODE (1985), que democratiza el funcionamiento de los centros escolares, garantiza la participación libre de los agentes escolares, pero también legitima por mucho tiempo el modelo dual

28 Cfr. García-Gómez, Soledad: «Dos hitos en la historia reciente de la formación permanente del profesorado en España: la creación de los Institutos de Ciencias de la Educación y la configuración de los Movimientos de Renovación Pedagógica», Revista de Educación, 317 (1998), pp. 145-156.

29 Como botón de muestra baste recordar la Orden de 8 de junio de 1983 por la que se convocan ayudas económicas a los Movimientos de Renovación Pedagógica para la realización de Escuelas de Verano durante 1983. El número de los Mrp que solicitan las ayudas es de 35, si bien el número de los que tiene constancia el MEC es de 46, para el curso 198I-82, que computan entonces 6.060 socios. 
de centros educativos públicos, concertados y privados $^{30}$. Y en este proceso de reformas educativas la posición y desempeño pedagógico autónomo de los MRP va dejando paso, poco a poco, a pautas y formas de gestión educativa menos autónomas y más formalizadas desde arriba. Tal vez había pasado el tiempo histórico de los MRP y solo podían continuar existiendo y enriqueciendo la educación, en el mejor de los casos, grupos más pequeños de renovación pedagógica, muchos de los cuales han mantenido vitalidad hasta nuestros días, por fortuna.

\section{Punto final y... un poco seguido}

Un movimiento social amplio en educación, en este caso uno o varios MRP, nace, emerge y alcanza dimensiones impensables (o grandes) cuando confluyen varias de estas grandes situaciones: no existen estructuras públicas y reconocidas de canalización de la participación política y social (partidos políticos, sindicatos), o estas se han corrompido (o proceden de una larga dictadura) y son visualizadas como inoperantes; se palpa en el ambiente una indudable carga utópica sobre la educación y de deseo de participación en el proyecto educativo colectivo; a ello se añade un plus de contenido descentralizador sobre el sistema educativo, o una cierta carga nacionalista existente o construida en el marco de la Constitución de 1978 y desde la potente influencia del nacionalismo catalán y sus MRP sobre el conjunto, léase Rosa Sensat en primer lugar.

A estas variables explicativas conviene añadir alguna más. Por ejemplo, las jornadas y seminarios libres y autónomos de los profesores se erigen en espacios privilegiados de sociabilidad, para cultivar la amistad, a veces el encuentro amoroso, la música alternativa, la lectura crítica, las novedades pedagógicas de editoriales de menor circulación, la conversación inacabada, donde afloran sentimientos de expresión libre, el debate político, la defensa de la lengua propia, el compromiso solidario con quienes más lo necesitan y con las causas que puedan parecer perdidas o motivadoras más allá de los programas políticos oficiales de los partidos (léase, entre muchas posibles, la lucha contra la OTAN, contra la energía y las centrales nucleares, a favor del divorcio, de la objeción de conciencia, contra el militarismo armamentista, la libertad sexual, derechos del mundo rural, el ecologismo, las universidades populares, la pedagogía de la liberación, experiencias de educación autogestionaria). En otras palabras, los MRP son expresión pública de un momento histórico especial, próximos a otros movimientos sociales que funcionan con mucha vitalidad en un contexto muy propicio para la emergencia de libertades de todo tipo a la salida de una dictadura férrea, y con la aspiración colectiva, a veces romántica, de construir un mundo nuevo, una sociedad diferente y más justa, en este caso desde procesos de cambio en la política educativa y de renovación pedagógica.

3. VArela, Julia: Las reformas educativas a debate (1982-2006), Madrid, Morata, 2007. 
Tal vez la expresión «el abrazo del oso» que hemos utilizado para explicar de forma más gráfica el tema de la progresiva fagocitación de los MRP, o muchos de sus cuadros, sea algo exagerada. Sin duda es una forma de hablar, porque fueron varias las circunstancias que intervienen en ese complejo proceso, y el contexto de fondo va cambiando mucho, a medida que se regularizan la democracia y sus instituciones. La reducción final de los MRP a grupos de renovación pedagógica más pequeños en su composición, y más centrados en aspectos pedagógicos específicos, cuando partidos y sindicatos canalizan otras aspiraciones existentes o nacidas incluso en el seno de los MRP, en nuestra opinión no es más que la constatación de un proceso sociopolítico vivido en la España de la transición que se canaliza por los cauces naturales que inicialmente no existían, pero que se fueron creando. Se constata, una vez más, que las relaciones entre lo educativo y lo pedagógico con el contexto ciudadano de referencia, en todas sus dimensiones, es siempre real, porque lo educativo en un sentido pleno nunca puede ser autónomo e independiente de lo sociopolítico y las condiciones materiales de la sociedad donde se inserta.

Habrá que dejar para otra ocasión el estudio del devenir posterior de los conocidos como MRP en la coyuntura de la transición educativa, en algunos casos ya convertidos en grupos de renovación activos o residuales, y en otros casi extinguidos o desaparecidos. Los profundos procesos de reformas vividos por el sistema educativo español a partir de 1985 en lo normativo, organizativo y en el debate científico pedagógico nos invitarán a revisar con cautela qué fue y qué se entiende por MRP en el presente siglo XXI, con independencia de constatar la aparición de numerosas iniciativas de innovación pedagógica en las últimas cuatro décadas ${ }^{31}$. Y sobre todo para comprender que con seguridad es irrepetible aquel extraordinario y original movimiento social y educativo de los MRP, tan activo y necesario para la educación y la sociedad en la España de los años 1970-1985.

3 Cfr. Pericacho Gómez, Francisco Javier: «Colectivos, centros e iniciativas de renovación pedagógica actuales en España. Señas de identidad e ideario pedagógico», Temps d'Educació, 48 (20I5), pp. 7I-90. 